\title{
DER in Portugal: State-of-the-art of the Two Major Repositories in Elementary and Secondary Education
}

\author{
Cornélia Castro ${ }^{1}$, Sérgio André Ferreira ${ }^{1}$, António Andrade, ${ }^{2, *}$
}

\author{
${ }^{1}$ School of Education and Psychology, Portuguese Catholic University, Porto, 4169-005 Portugal \\ ${ }^{2}$ School of Economics and Management, Portuguese Catholic University, Porto, 4169-005 Portugal
}

\begin{abstract}
In the last decade, there has been an expansion of Repositories of Digital Educational Resources (DER), funded and stimulated by government authorities and non-profit institutions, in order to publish, collect, d istribute and preserve DER. In this environment, inspired by the Open Content Movement, it is recognized the importance of the vast heritage of DER, produced by the collective intelligence, for pedagogical innovation. Following this trend, in Portugal, about three years ago, two repositories were created at the elementary and secondary education levels: Schools Portal, of Government responsibility with a generalist vocation, covering the entire spectrum of the curriculum and the House of Sciences, headed by the Calouste Gulbenkian Foundation, which is a private institution of public utility, and dedicated to the areas of natural and exact sciences. In this study the state of the art of these two repositories is presented once they are the ones most visible in Portugal in what concerns the main dimensions that interfere on their quality. The methodology of data collection was based on the analysis of the portals from the point of $v$ iew of the producers and users of the DER of the repositories. The main results and conclusions are presented and considerations about the factors that in the future may contribute to the sustainable improvement of some of the characteristics of the repositories covered in this study are stated.
\end{abstract}

Keywords Digital Educational Resources, Evaluation, Quality, Repositories

\section{Introduction}

During the 1990s, the funding for information technology in education primarily emphasized access to computers and the basic literacy for their use[1]. Since then, the social, cultural, economic and technological transformation, in this era of globalization, has not ruled out Education or educational systems. The technologies require us therefore to think that we need a new pedagogy based on interactivity and the development of autonomous capacity to learn.

In 1992, when the World Wide Web was launched, open information resources rapidly became freely available, although they were of widely varying quality. With rare exception, the available materials neither promoted enhanced learning nor incorporated the latest technological and pedagogical advances. Educational institutions and publishers, lack of quality assurance for the content, and information overload also impeded the educational impact.

Later, in 2002 the Educational Program of the Hewlett Foundation introduced a major component into its strategic plan Using Information Technology to Increase Access to High Quality Educational Content[1].

According to Maron et a1.[2], "The past decade has

* Corresponding author:

aandrade@porto.ucp.pt (António Andrade)

Published online at http://journal.sapub.org/edu

Copyright (C) 2012 Scientific \& Academic Publishing. All Rights Reserved witnessed a rush to create digital content in the not-for-profit sector, as organizations from a wide range of communities - from cultural heritage, to health care, to education and scholarship - have come to embrace the internet as a means to publish, collect, distribute and preserve the fruits of their work" $[2, \mathrm{p} .10]$.

The term Open Educational Resources refers to educational resources (lesson plans, quizzes, syllabi, simulations, etc.) that are available for free to use, reuse, adaptation, and sharing. That designation was first used in July 2002 during a UNESCO workshop on open courseware in developed countries. Many of its definitions include content, software tools, licenses and best practices. Two major inspiring projects, that deserved much attention, were Wikipedia (in 2001) due to its rapid development and the pioneering project MIT OpenCourse Ware (in 2002)[3] which had a growth that was not expected when the idea was proposed[4].

Thus, the use of the web as an educational tool provided teachers with a wide range of new and exciting experiences in the teaching and learning process which are not possible in a traditional classroom[5] such as access to information anywhere and at anytime, online presentations, activities based on interactive tasks and an effective propagation of information.

The publication of online content has grown so much that the 2010 edition of the Horizon Report[6] refers to the Open Content as an emerging trend. In fact, we are witnessing a 
growing volume of digital content from various sources [7] in the Educational sector.

The repositories are online systems intended to archive, preserve, make available and disseminate the intellectual output of a community, available in a digital space where data and information are stored and updated $[8,9]$ or "digital store boxes that host collections of digital resources in a learning object format: i. e. resources that are designed to be integrated, aggregated and sequential in an efficient way to produce "units of learning" that are meaningful to learners" $[10$, p. 3].

Sharing of Digital Educational Resources (DER) in the cloud ("The cloud is a term used to describe the vast collections of networked computers, typically housed in regionally distributed and redundant data centres that comprise the totality of the Internet" $[11$, p. 10]) is performed in two ways: i) informally, resulting from personal initiative, in which the author simply makes his resource available on the web, through social networks, blog or personal site and ii) via the government or an institution, in which central or regional educational services, foundations, libraries, among others, publish the DER through the respective electronic repositories.

This environment of sharing facilitates access to a wide range of resources by teachers, maximizing the exploration of a mo re diverse content, which leads to an improved quality of education. Thus the Open Content movement has numerous and potential implications for education, since it reveals itself as an educational tool with transforming power: it accelerates the decentralizing of formal education and it provides educational activities and even cultural activities more broadly [7, 12].

The DER in addition to their instructional value are powerful tools, not only to improve the learning experiences but also to improve educational results. Their application in the school environment is, according to literature, relatively recent[13], which can be explained by the fact that their creation was more in the hands of technical experts than in the hands of teachers (and/or students). Thus, the perception of the added value that the use of DER brings to education requires the understanding of the pedagogical is sues associated with them and not better or improved technology[14]. In fact, the DER are well structured materials, which are easily upgradeable and their pedagogical value is that they allow the discovery and exploration of issues through interactive, flexible, differentiated and motivating activities [15].

Considering the context as the set of relations between the pupils and the surrounding elements in a position of teaching and learning, then the DER can be considered as an element in the context, and as such it becomes a source of learn ing, via the interaction between students [15].

Although the theme of the DER and repositories is among the educational issues currently under debate, the idea of creating digital learning resources for the purpose of reuse has been on the agenda of Education since the 90s of the XX century. Initiatives such as the so called OpenContent held in 1998 at Utah State University, USA, were the initiators of the Open Content movement. Even then it seemed obvious that as soon as teachers could search the web for resources to teach, the culture of publishing and reuse of these materials would be developed[12].

If this movement exists, if there is even a governmental and an institutional commitment it is because of the resulting added value. Dyer and Nobeoka indicated that knowledge sharing can be defined as the set of activities that allow commun ities of people to work together, to improve the capacity of organizational learning and to increase the ability to achieve individual and organizational goals[16]. Many other researchers have reinforced the idea that the organizacional value of employees' knowledge increases when this knowledge is shared[17]. On the other hand, the DER also allow wider access to learning for all, but especially for non-traditional groups of students, enabling in an efficient way, the promotion of lifelong learn ing and building bridges between non-formal, informal and formal education[7,12].

Aspects such as: the visibility; acceptance of policies for the publication of the resource; scientific rigor; legal aspects; safety rules; authenticity and integrity of data can contribute to a greater diffusion of the DER, with quality assurance in what concerns the DER present in repositories of governmental or institutional origin. These aspects are not attributes of the DER published in the non-formal way.

However, quality does not depend only on the properties of the educational resource. It is also closely related to how the resource is used and also to the specification of a number of requirements such as the interface between the user and the resource, the possibilities and limitations of the resource or its potential for the learning process [18].

In fact, the availability of DER in a repository with more controlled quality and intended for target audiences are two strong increases in the value of the repositories.

In this study, we propose to make an assessment of two repositories of DER, a governmental one and an institutional one, both created in 2009 in Portugal: one by the Ministry of Education (Schools Portal - Portal das Escolas) and the second one created by a private institution (Calouste Gulbenkian Foundation) of public utility (House of Sciences - Casa das Ciências). We considered these as the main repositories due to: the diversity of the types of resources, the curricular areas covered, the number of publications, the number of downloads made and the number of visits.

We established as the research question "What is the state-of-the-art of the two Portuguese DER repositories of greater visibility in elementary and secondary education?", aiming to make a comparative analysis of repositories as far as collaboration of authors and access for users are concerned.

\section{Strengths and Limitations of Repositories}


The existence of a vast universe of resources found on the web is an invaluable asset, since it constitutes the basis for the emergence of a "collective intelligence". However, this information density also poses difficulties in navigation in the cloud, namely: i) in the search, selection and assessment and ii) in the control of property rights, privacy, ethics and values.

The conception and development of a repository of DER must therefore be anchored in a concept that allows the understanding and the communication of the repository's central object: the DER[8]. In fact, the repositories resulted fro $m$ the need to systematize the prolife ration of digital resources from all regions of the globe and from many different communities and cultures. They represent online systems designed to archive, make available and spread the intellectual output of a community, available in digital format[8], a digital space where data and information are stored and updated[19].

\subsection{Strengths}

The strengths of a repository are several, but we stress some of the established by the Organization for Economic Co-Operation and Development (OECD) as well as the ones mentioned in a recent report by the JISC[20]:

- To facilitate change in teaching practices;

- Benchmarking teachers' practices in terms of content, approach and general quality;

- To encourage more interactive and constructivist teaching practices;

- To induce and streamline the production and use of tools, content, resources and information in digital/electronic support;

- To save time and effort in providing good DER in teaching activity;

- To enable the reuse of resources with quality and diversified which, in many cases, it would be impossible to create by the teacher-user due to lack of skill;

- To promote the use of DER as a complement or substitute of teaching in the classroom;

- To facilitate collaborative approaches in teaching [21];

- To encourage networking and collaboration between teachers;

- To minimize the info exclusion, allowing remote and low cost access to content, modules and courses;

- To foster the inclusion of people with special needs in teaching and learning;

- To develop and strengthen a culture of lifelong learning.

\subsection{Limitati ons}

Previous studies have identified several barriers that limit access and use of repositories (e.g.:[7, 12, 20, 22, 23]), in particular of the following nature:

- Pedagogical: tiny amount of resources in some subjects and problematic interdiscip linary research;

- Technical: unavailability of broadband, poor indexing;

- Discoverability resulting from poor indexing and from low potential of some search engines (which is often mitigated by word of mouth from teachers of the same community);

- Econo mic: lack of resources to invest in hardware and software required to develop and to share DER; difficulties to cover the costs of developing educational resources and sustain an Open Content project in the long term;

- Social: lack of skills to use technical inventions; tolerance to the use of technology;

- Cultural: resistance in the sharing or use of resources produced by other teachers or organizations;

- Political;

- Legal.

Given the strengths and limitations listed, it is important that those who are responsible for the repositories create conditions that foster their added-value, minimize some of the obstacles, be able to properly organize hundreds or thousands of content, and to encourage their gathering, to allow for greater and effective res earch.

\section{RED In Portugal: Major Repositories In Elementary And Secondary Education}

As already mentioned, the object of this study are the two main repositories DER of greater visibility in Portugal, in terms of elementary and secondary education: "Portal das Escolas", governmental and "Casa das Ciências", institutional for the universe of 179956 teachers of public and private schools in mainland Portugal, Madeira and the Azores[24].

\subsection{Schools Portal (Portal das Escolas)}

Following the international trend of development and promotion of virtual platforms of knowledge, the Portuguese Government considered that the creation of a virtual platform of knowledge would play a critical role in the process of technological modernization of education. This decision also took into account the low utilization rate of DER in Portugal, diagnosed in a study conducted under the Technological Plan for Education[8].

In fact, we are witnessing the first steps in Portugal in the disclosure and use of e-learning platforms, implemented in more than $50 \%$ of elementary and secondary schools. The open source platform Moodle LMS has been the most widely used[7, 21].

The Schools Portal aims to establish itself as the reference site for schools and as the largest online collaborative network for Education in Portugal[25]. Through this portal, teachers in Portuguese public schools can access, produce and publish DER (text, images, videos or music) and benefit from a wide range of online services, adding value to the process of teaching and learning[25].

This repository provides reliable and useful material and information for school, academic and professional life, with 
the Ministry of Education and Science adopting mechanisms for validation of the available educational resources[25]. It allows access to thousands of quality digital educational resources in all curricular areas, adapted for use in the classroom in Portugal[25], also by binding to the International DataBase of Educational Objects.

Everyone can have access to the resources available on the Schools Portal, since navigation is not subject to registration. Registration is only reserved for teachers who wish to upload a resource or to apply for certification of ICT skills - level 1 . This certification is a program created with two objectives: i) to generalize training and certification of ICT skills in the educational community and ii) to promote the use of ICT in the teaching and learning process and in school management[26].

In 2011, the Portal started offering the service of electronic enrolment in pre-school and in the $1^{\text {st }}$ year of elementary school.

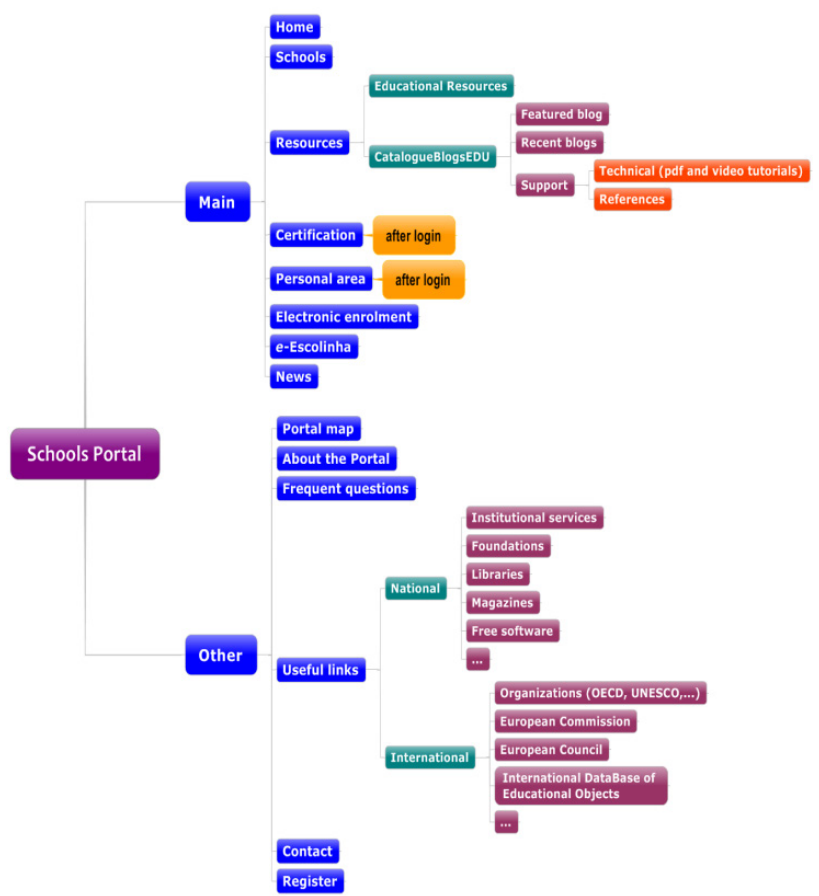

Figure 1. Information on the webpage of the Schools Portal

Taking as a basis that the educational blog has been asserting itself in the Portuguese educational context as a possible tool to integrating ICT, even in 2011, more precisely in March, the catalogue of Educational Blogs was launched. This catalogue is included in the area of "Resources" of the Schools Portal. For a blog to be published it must meet certain criteria which are presented in a video in the Support Area (Apoio). Also in this area, tutorials on how to build a blog in an educational context and on how to register it in the Schools Portal are presented, in pdf format and video. For the registered blogs the label "BlogsEDU" is assigned as well as an identifying number. The author of the blog at the time of submission should also indicate the curriculum area(s) for which it is intended, the target audience, its age and educational level. Being published, the language, con- text, tags, the respective $u r l$ and the name of the teacher responsible for the publication, the educational establishment to which he/she belongs and the date of publication of the blog are also given.

Table 1 presents some demographic data concerning Schools Portal.

Table 1. Demographic data concerning "Portal das Escolas"

\begin{tabular}{|c|c|}
\hline Teachers in Portugal (Continent, Azores and Madeira) & $156528^{*}$ \\
\hline Number of users & $83000^{+}$ \\
\hline Number of published DER & $1411^{*}$ \\
\hline Number of published blogs & $248^{*}$ \\
\hline Facebook fan page & Not applicable \\
\hline *Portal das Escolas, $22^{\text {nd }}$ March $2012 ;{ }^{+}$GEPE, $29^{\text {th }}$ May 2011 \\
\hline
\end{tabular}

Figure 1 presents the organizational structure of the Schools Portal website, which aims to allow the registration of teachers of private schools and the teachers of Portuguese abroad, and to provide a web hosting to all schools, in the near future.

\subsection{House of Sciences (Casa da Ciências)}

The "Casa das Ciências" is a project of the initiative of the Calouste Gulbenkian Foundation (a Portuguese private organization with public utility whose statutory aims are Art, Charity, Science and Education). As a result of the support this institution has been providing to the quality of Education in Portugal, the project "Casa das Ciências" has emerged.

This project defines itself as an integrating and amplifying vehicle of the current efforts in the use of Information Technology in the teaching and learning process made by a number of different agents and which results are scattered. This repository is designed to give visibility and usefulness to the efforts of many teachers, recognizing their well deserved merit and becoming a reference website for all science teachers in Portugal. As a portal of teachers for teachers [27], it also provides materials that teachers themselves find useful and effective for their professional activity, where they can share ideas and experiences on those materials and how to use them.

In the repository, all the resources submitted are evaluated by referees (125 actives) from a scientific and educational point of view, in logic of peer-review, in analogy with the usual scientific publications[27]. This quality control of the objects submitted conforms to a set of rules established in a regulation.

All teachers that, each year, submit resources to the repository are candidates for annual awards set up by FCG: Excellence, Distinction, Merit and honours. The nominees are chosen by a jury, whose constitution is established in a regulation. Following this logic, it is stated on the "Who are we" tab (Quem somos) that these mechanisms naturally have an expected impact on the curriculum of the authors, therefore giving value to the work of the creators of DER in face of the repository users.

In this repository, in addition to the DER authored by Portuguese teachers, materials created by foreign authors 
are provided. These resources are translated and they are available in the repository because the coordinator office and technical committees recognize their relevance. The teachers who are authors of DER and are appointed for the annual award of the House of Sciences, are invited by the coordinator office to be part of the body called "Representantes da Casa das Ciências" (Representatives of the House of Sciences) who have as their mission to promote and foster the use of the House of Sciences both as a user and a creator of DER, helping to give visibility to the repository. It is also the House of Sciences' strategy to have regular meetings within the WikiSciences, bank of images and the technical committees and an annual meeting with its collaborators, including their representatives. These meetings, which are an innovative and fruitful strategy, are intended to allow the exchanging and discussing of ideas on how to improve the impact and visibility of the repository in the Portuguese community of teachers. For example, we can refer that it was this logic of sharing that led to the creation of a forum of two kinds: one general and another only for the interaction between representatives of the House of Sciences, in order to discuss more often all issues that may contribute to the improvement of the repository.

Figure 2 shows the organizational structure of the House Sciences' site:

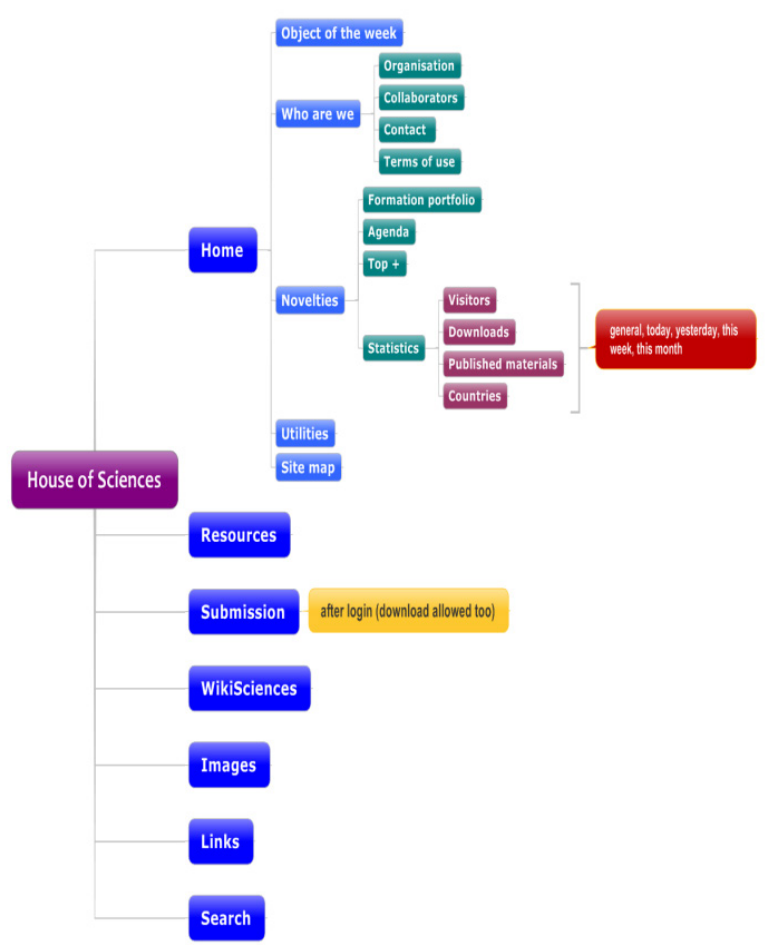

Figure 2. Information on the House of Sciences' website

On May $30^{\text {th }} 2011$, WikiSciences, an online encyclopaedia, was launched, which currently has 558 pages and in which all items are also evaluated by peers. Being a wiki, all items are open to criticis $m$ and improvement, in a collaborative perspective. In 2012, a database of images was launched (illustrations, diagrams and photographs) that can be used, in some way, in teaching, and which submission process is similar to that established for the DER (currently they are about 530, in areas such as chemistry, biology and geology).

Table 2 shows the demographic data relating to users of the House of Sciences, which has also been in social media Facebook since 2012.

Table 2. Demographic data of "Casa das Ciências"

\begin{tabular}{|c|c|c|}
\hline \multicolumn{2}{|c|}{ Total users } & 9596 \\
\hline \multirow{2}{*}{ Gender } & Male & $30 \%$ \\
\hline & Female & $70 \%$ \\
\hline \multirow{4}{*}{ Qualifications } & Bachelor & $3 \%$ \\
\hline & Graduation & $75 \%$ \\
\hline & Mst & $17 \%$ \\
\hline & $\mathrm{PhD}$ & $4 \%$ \\
\hline \multirow{6}{*}{ Level taught } & Elementary 3-5 & $1 \%$ \\
\hline & Elementary 6-10 & $6 \%$ \\
\hline & Elementary 11-12 & $12 \%$ \\
\hline & Elementary $13-15$ & $27 \%$ \\
\hline & Secondary & $54 \%$ \\
\hline & Higher Education & $1 \%$ \\
\hline \multirow{7}{*}{ Subject } & Elementary 11-12 & $6 \%$ \\
\hline & Math and Nature Sciences & $11 \%$ \\
\hline & Physics and Chemistry & $30 \%$ \\
\hline & Biology and Geology & $22 \%$ \\
\hline & Maths & $19 \%$ \\
\hline & Computing & $2 \%$ \\
\hline & Others & $10 \%$ \\
\hline \multirow{7}{*}{ Facebook fans } & Portugal & 667 \\
\hline & Brazil & 22 \\
\hline & Angola & 1 \\
\hline & Canada & 2 \\
\hline & Argentina & 1 \\
\hline & Sweden & 1 \\
\hline & Total & 694 \\
\hline
\end{tabular}

\section{Methodology}

This study was aimed to characterize the two major repositories of DER of the elementary and secondary schools in Portugal, assessing the key dimensions that affect their quality. For this purpose we chose a descriptive study that allowed us to obtain a broad view of the problem. For the investigation to take place it was necessary a prior identification of the dimensions that were going to be evaluated[28].

In this sense, the "Guía para la Evaluación de Repositorios Institucionales de Investigación" (GERII), was adapted. This guide was jointly published by the Ministry of Science and Innovation of Spain and other relevant organizations in the field of Education, Sciences and Technology[29]. The GERII includes several guidelines for the creation and evaluation of a repository. It brings together a set of 31 evaluation criteria, spread over seven dimensions that any good repository must meet and it was therefore considered an excellent base document for the analys is intended.

In this study, we decided to make some adjustments to 
the evaluation model followed by GERII. Thus, only five of the dimensions present in GERII were considered, leaving out the dimensions "Interoperability" and "Security, authentication and data integrity" because: i) as they are essentially technical dimensions, they did not fit in the set methodology for collecting data and ii) the evaluation of the repositories was only intended to be done fro $m$ the perspective of either the producer and the user.

Figure 3 summarizes the dimensions considered.

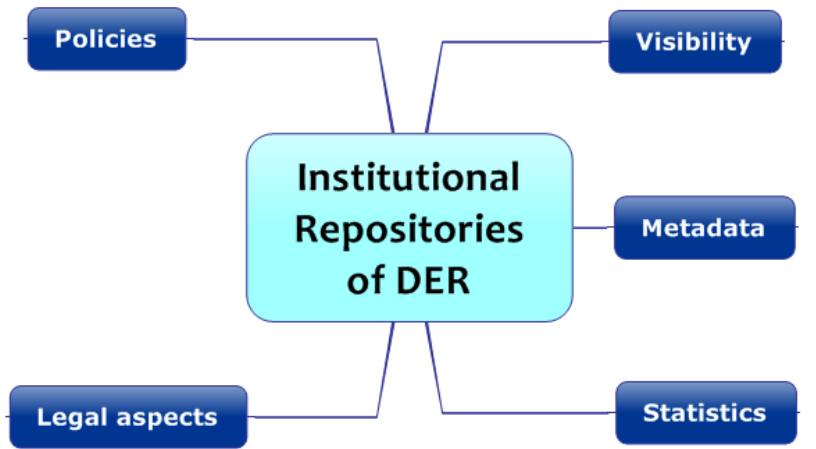

Figure 3. Dimensions for evaluating Repositories of DER for elementary and secondary schools in Portugal

Presented in table 3 and in accordance with the GERII guide, are the criteria to be considered in each one of the five evaluation dimensions considered in this study.

Table 3. Dimensions to evaluate

\begin{tabular}{|l|l|}
\hline Dimension & Evaluation Criteria \\
\hline Visibility & $\begin{array}{l}\text { Visibility in major search engines; there is a standard } \\
\text { name and an appropriate } \text { url; there are incentives for } \\
\text { participation and information on how to submit. }\end{array}$ \\
\hline Policies & $\begin{array}{l}\text { Disclosure of the mission, object ives and funct ion; } \\
\text { information on who can submit, what can be submitted } \\
\text { and in which formats; information on archive policies of } \\
\text { documents and preservation of content; ways of contact } \\
\text { and support. }\end{array}$ \\
\hline $\begin{array}{l}\text { Legal } \\
\text { Aspects }\end{array}$ & $\begin{array}{l}\text { Information on existing intellectual property of DER in } \\
\text { the repository. }\end{array}$ \\
\hline Metadata & $\begin{array}{l}\text { Information about the formats used; use of binders or } \\
\text { definition of a policy of content indexing. }\end{array}$ \\
\hline Statistics & $\begin{array}{l}\text { Mechanismsto register logs for accessing the server and } \\
\text { uploads, downloads and use of the DER. }\end{array}$ \\
\hline
\end{tabular}

The methodology of data collection was based on the analysis of the websites of repositories. Thus, each repository was classified for each criteria of the five dimensions considered. In order to synthesize the presentation of results, a SWOT table was used: (S - Strengths; W - Weaknesses, $\mathrm{O}$ - Opportunities and $\mathrm{T}-$ Threats).

The evaluation was carried out in the perspective of the producer and the user of the DER repository, that is to say, to perform uploads or downloads of DER from the repository and to see all the information available and relevant for the teaching and learning process.

\section{Results}

The results of this research have allowed a comprehen- sive assessment of the quality of the two Portuguese DER repositories for teaching at elementary and secondary schools, from the perspective of the authors and the users. In the evaluation process, the five dimensions considered, allowed an approach to key issues related to user access and collaboration between the authors/producers of DER.

Table 4 summarizes the results of the dimension "Visibility".

Table 4. Dimension: Visibility

\begin{tabular}{|l|l|}
\hline Advantages & Limitations \\
\hline $\begin{array}{l}\text { Excellent visibility in the search engines. } \\
\text { Normalized name of "Portal das Escolas" and } \\
\text { "Casa das Ciências", facilitating identification; }\end{array}$ & $\begin{array}{l}\text { No reference is } \\
\text { made to the }\end{array}$ \\
adequated $u r l$. & repositories on \\
Incentives for part icipation in the repository. & the homepage \\
Clear information on how to submit DER. & of the website \\
Video demonstration on the process of submiting a & oftheir holders. \\
resource (House of Sciences) or a blog (Schools & \\
$\begin{array}{l}\text { Portal). } \\
\text { Representatives of House of Sciences. }\end{array}$ & \\
\hline
\end{tabular}

The two analysed repositories have good visibility on the web. When a search of the repositories is made by "name", in the five most commonly used search engines in Portugal (Google, Bing, Yahoo, AOL and Ask)[30], both appear as the first result.

The urls of the repositories: https://www.portaldasescolas .pt/ and http://www.casadasciencias.org/ are adequate, allowing for easy memorization. The fact that the homepages of the Ministry of Education and Science and of the Calouste Gulbenkian Foundation make no reference, in their internal search engines, to its portal of repositories, does not contribute to the valorisation of those, and it is possibly indicative that the repositories are not central to the their policies. Furthermore, this is an action that facilitates the reduction of the visibility of the repository for the target users. If, for example, a visitor to the organization's homepage was not specifically looking for the repository, but he/she found that indication there, he/she would be given the possibility to click to the repository, which would be a valuable way to disclose the repository to potential users. However, it is important to clarify that the "Portal das Escolas", of the Ministry of Education and Science, belongs to the organic unit "Direção-Geral de Estatísticas da Educação e Ciência" (DGEEC, former GEPE) and on this unit's homepage there is a reference to the repository. However, for the reasons stated above, we believe that the repository would achieve greater visibility and recognition if there was, cumulatively, a reference to it on the homepage of the Ministry of Education and Science.

On the evaluated repositories information on how to submit resources is given, and messages to encourage participation and collaboration in them are broadcasted. In the implementation phase in which we are (the two repositories are recent as they were only created about three years ago), we believe that all information that enables enlightenment and awareness for the use of repositories is particularly important. 
In table 5 the main results of the dimension "Policies" are summarized.

Table 5. Dimension: Policies

\begin{tabular}{|c|c|}
\hline Advantages & Limitations \\
\hline $\begin{array}{l}\text { The mission, object ives and functions of the re- } \\
\text { pository are present. } \\
\text { It is stated how users can upload the content, what } \\
\text { kind of content is accepted and in what formats. } \\
\text { There is a requirement to register to download a } \\
\text { resource (House of Sciences) or to upload aresource } \\
\text { (in both reposit ories). } \\
\text { Ways to cont act support are available. }\end{array}$ & $\begin{array}{l}\text { There is not } \\
\text { a public } \\
\text { policy of } \\
\text { preserving } \\
\text { content. }\end{array}$ \\
\hline
\end{tabular}

The existence of information concerning the objectives, scope and functions of the repository, in the studied repositories, is important because it not only allows the visitor to know whether he/she falls on the target audience, but it also favours the process of decision making on how he/she may potentially participate (as a user and/or author of DER).

The establishment of policies on who can upload, what kind of content is accepted and the provision of support via website and e-mail, are factors that facilitate collaboration.

The requirement to register in order to obtain permission to download a certain resource, presents its elf as an advantage. This way, the user community of the repository will increase and, consequently, the spirit of sharing and collaboration among all teachers is stimulated, thereby enhancing the visibility of the repository. Moreover, this action may also lead a mere user to become a producer and therefore enrich ing the repository.

As a limiting factor in th is dimension, we can point out the fact of not having been released publicly, a policy of preservation of content. The fact that the entity owning the repository does not declare its commitment to make content available on a permanent basis and to take measures for its preservation (in case of migration, for example) to ensure access to them and create and maintain file formats, can contribute to reducing the confidence of authors and therefore inhibiting their collaboration.

From the point of view of the "Legal Aspects", the evaluated repositories meet the basic requirements to ensure copyright, according to the summary presented in table 6 .

Table 6. Dimension: Legal Aspects

\begin{tabular}{|l|l|}
\hline Advantages & Limitations \\
\hline Confirmation by the author, during the submission & \\
process, that the material does not go against any & \\
intellectual property rights. & Not identi- \\
Author's permission to allow distribution of content. & fied. \\
Existence of information on copyright ofthe type & \\
Creative Commons. & \\
\hline
\end{tabular}

The author, during the submission process, confirms that the DER does not infract any intellectual property rights of others, granting permission for distribution of his own resource. These declarations are essential to safeguard legal is sues and also because they favour the spreading of ethical principles in the production and use of resources. The existence of information about the Creative Commons license also fits within this framework of legality, responsibility and ethical principles.

Table 7. Dimension: Metadata

\begin{tabular}{|l|l|}
\hline Advantages & Limitations \\
\hline $\begin{array}{l}\text { There are standard procedures for indexing DER } \\
\text { (indication of aut hor, description, theme, subject, }\end{array}$ & \\
grade, keywords, audience, resource type and time, & \\
among others). & Not identified. \\
$\begin{array}{l}\text { The House of Sciences also allows a Google search. } \\
\text { Themetadata enables the type of search by standard } \\
\text { criteria. }\end{array}$ & \\
\hline
\end{tabular}

The huge volume of DER available in the repositories makes it fundamental that they are described by metadata (table 7). These allow the recognition of repositories for humans and computers, so that they can be located using different criteria. Of little use are the resources that cannot be easily searched, so the is sue of metadata is of paramount importance.

In the two repositories analysed, at the time of upload it is requested that authors classify the resources through a series of standardized criteria (table 7). The criteria differ slightly in the two repositories and include items such as author, description, theme, subject, grade, keywords or time, for example. Similarly, the repositories allow a search of DER on the same criteria.

Finally, the dimension "Statistics" (table 8), is also important, both from the perspective of the author and user.

Table 8. Dimension: Statistics

\begin{tabular}{|l|l|}
\hline Advantages & Limitations \\
\hline $\begin{array}{l}\text { Report on the number of available and/or } \\
\text { published resources. }\end{array}$ & \\
$\begin{array}{l}\text { Report on the number of downloads (House of } \\
\text { Sciences) and/or views (Schools Portal) made. }\end{array}$ & $\begin{array}{l}\text { Statistics are not } \\
\text { available in the } \\
\text { SchoolsPortal, }\end{array}$ \\
$\begin{array}{l}\text { Indicates the number of visitors (general, } \\
\text { today, yesterday, this week or this month, in the } \\
\text { case of the House of Sciences). }\end{array}$ & $\begin{array}{l}\text { user's login is } \\
\text { made. }\end{array}$ \\
$\begin{array}{l}\text { Presents the most recent DER, top rated and/or } \\
\text { most popular. }\end{array}$ & \\
\hline
\end{tabular}

From the perspective of the user, when a teacher uses a repository, the available statistics relating to a particular resource, allow him/her to see if the resource he/she is looking for meets the requirements he/she wants for its use in the context of the classroom. Knowing, for example, which resources have the most votes, can help him/her to decide whether to download a given resource, helping to give visibility to it. From the author's point of view, knowing the number of downloads of the resource he/she submitted in a given repository, will give him/her feedback on the interest that it aroused in the community of his/her peers and will stimulate $\mathrm{him} / \mathrm{her}$ to produce and share more resources.

In addition, the knowledge of the number of $\mathrm{v}$ isitors to a repository helps the teacher to understand the importance of it and to start considering it as a tool that he/she may use not only to facilitate his/her work on class preparation but also in the sense of diversifying his/her practices.

In table 9 some indicators relating to the dynamics of ac- 
cess and use of the House of Sciences are summarized. These indicators are accessible to users who make the login in the tab "Statistics".

Table 9. Dat a from House of Sciences

\begin{tabular}{|c|c|c|}
\hline \multicolumn{2}{|c|}{ Total of visits since the beginning* } & 285119 \\
\hline \multicolumn{2}{|c|}{ Number of resources* } & 1636 \\
\hline \multicolumn{2}{|c|}{ Number of regist ered members* } & 9496 \\
\hline \multicolumn{2}{|c|}{ Users who downloaded materials* } & 5961 \\
\hline \multirow{3}{*}{ Accesses $^{\#}$} & Daily mean & $1000-1150$ \\
\hline & Weekly mean & $6000-7500$ \\
\hline & Total & 27434 \\
\hline \multirow{3}{*}{ Downloads $^{\#}$} & Daily mean & 180 \\
\hline & Weekly mean & 1250 \\
\hline & Total & 5133 \\
\hline \multirow{5}{*}{$\begin{array}{l}\text { Approved } \\
\text { materials }\end{array}$} & 2009 & 113 \\
\hline & 2010 & 103 \\
\hline & 2011 & 114 \\
\hline & 2012 & 2 \\
\hline & Total* & 332 \\
\hline \multicolumn{2}{|c|}{ Materials not approved since the beginning* } & $8,4 \%$ \\
\hline \multicolumn{3}{|c|}{${ }^{*}$ Data on the $19^{\text {th }}$ March $2012 ;{ }^{*}$ Data until February 2012} \\
\hline
\end{tabular}

From an analysis of those statistics, some aspects can be highlighted:

- The number of visitors, exceeding 285 thous and, seems relevant in a country with 179956 teachers (some visitors may be students, not teachers, or foreigners);

- The number of available DER is 1636 , only 332 resulting from the upload of registered members. From this we can conclude that $80 \%$ of the resources are made available by the system administrators and $20 \%$ are the result of submission by the users. This reveals a small contribution of users;

- The number of approved material has remained constant between the years 2009 and 2011 (mean: $\mathrm{n}=110$ ).

- There is a significant discrepancy between the number of hits and downloads made: only in $19 \%$ of the accesses, downloads are made. This may be explained by the fact that some resources may be viewed online - without authentication or registration - simply by activating the flag icon that appears next to the description of the resource (in the Portuguese flag the translated/adapted material can be seen and in the flag of the country of orig in, one is directed to the source material) when possible. It is, therefore, feasible to infer that the repository's users visualize resources to perform their evaluation in terms of interest for their teaching practices and will decide whether or not to download them.

- The rate of submitted materials that are not approved outright and not subject to peer-review is $8,4 \%$, corresponding to a typology of DER that does not meet the requirements of the regulation stipulated by the House of Sciences. This percentage is mainly affected by what occurred at the beginning of the repository due to a possible lack of knowledge of the regulation (sub tab in Terms of Use). Of the submitted DER, about $87 \%$ are returned to the authors with the description of the peer-rev iew that they have been subjected to and 3,5\% are not re-submitted. For this non re-submission two competing factors may contribute: i) the fact that the creator has to make some changes to his DER to bring it in line with the required quality standards, which would consume more of his time in a work schedule that is already heavily burdened for the Portuguese teachers and/or ii) the creator disagrees with the assessment that was done and decides not to re-submit the resource. Thus it seems that the authors of DER should pay more attention to the "Regulations of materials" in order to contribute to reducing the rate of resources returned and thereby enable a faster and increased share of DER to be published by the repository.

Figures 4 and 5 allow us to measure the characteristics of the DER present in the repository of the House of Sciences.

Figure 4 shows the distribution of DER by level of education. The main conclusion is that the more advanced the level of education, the greater the number of available DER: $73 \%$ for the secondary level (16-18 years old) and $21 \%$ for elementary levels. This is a situation that certainly deserves to be studied. Although the entity that owns the repository will make efforts to mobilize the interest of teachers in the elementary levels to the repository, it seems that there is still a way to go and new strategies can be developed to achieve that goal.

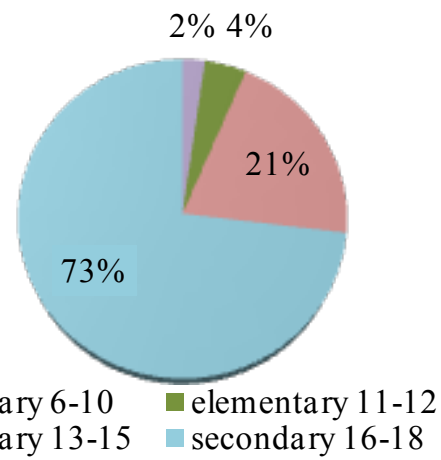

$\square$ elementary $6-10 \quad$ elementary $11-12$
$\square$ elementary $13-15 \quad$ secondary $16-18$

Figure 4. Distribution of RED by teaching level

In figure 5 the distribution of resources by subject is visible. It is worth noting that Physics has $57 \%$ of the available resources. This is a significant figure and it may be important to understand to what extent it has parallels in other realities or whether it is a reality located in this context, due to the criteria in DER selection.

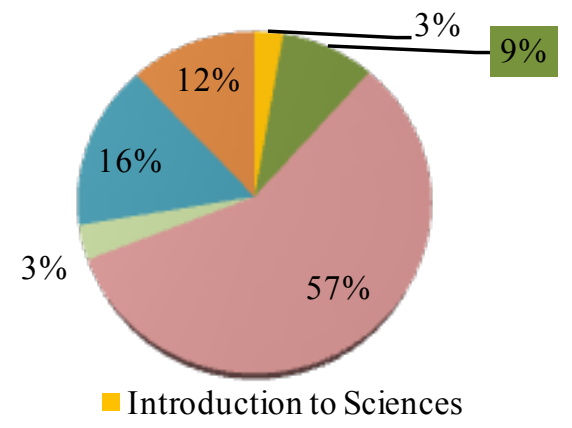

Figure 5. Distribution of DER by subject

Also, as shown in figure $6,80 \%$ of the DER of the "Casa das Ciências" are selected and made available by the people 
responsible for the repository.

From the analysis of figure 6 it is also possible to see that there is a demanding criteria to reward quality, as of the approved materials $(\mathrm{n}=332,20 \%$ of the total), only 23 (7 \%) were awarded.
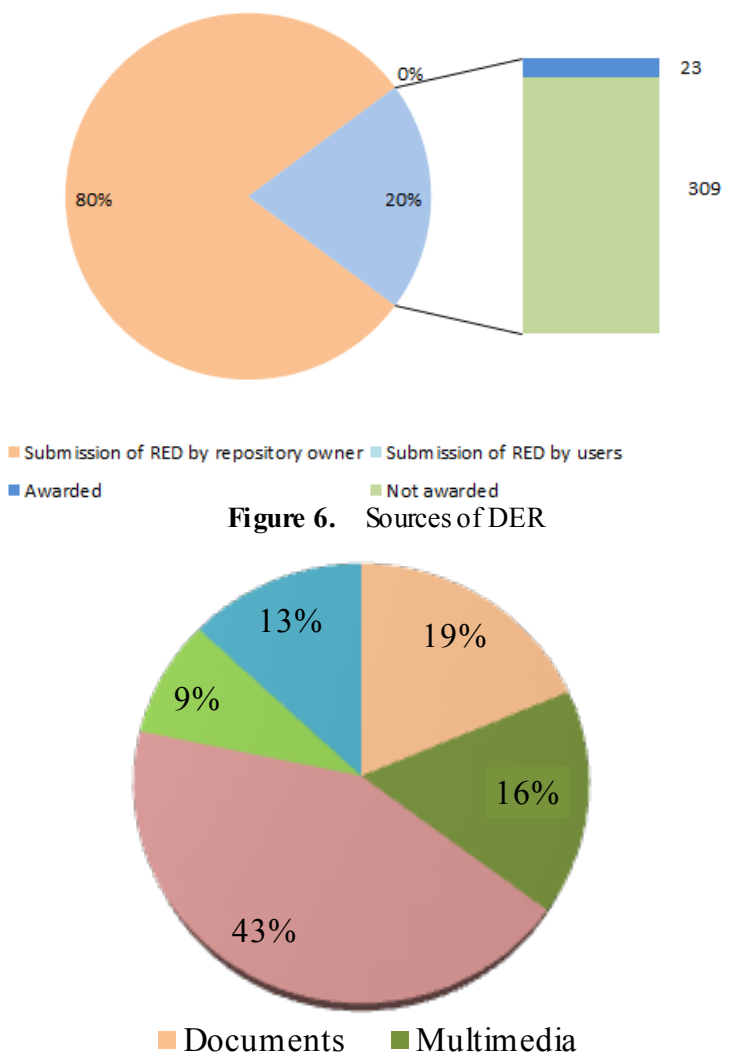

Figure 7. Distribution of DER by type

As far as the distribution of DER by type is concerned (Figure 7), it appears that the predominant type is the hypertext $(43 \%)$, followed by documents $(19 \%)$ and multimedia $(16 \%)$. The presentations $(13 \%)$ and the applications $(9 \%)$ are groups with lower expression. From this, it is inferred that the interactivity of resources will be privileged and the development of applications, by requiring more advanced technical knowledge has, therefore, less representativeness, with regard to the typology of the materials published.

\section{Conclusions}

The increased volume of DER in the web and their organization in repositories opens a window of opportunity for change in the education sector. The possibility for teachers to access a vast, varied and eclectic set of resources favours the diversification of strategies in teaching practice and stimulates the production, use and disclosure of DER.

Moreover, the repositories also contribute to the opening of the classroom to the world. In fact, by being available online, the DER can be accessed from anywhere, anytime and by anyone who has appropriate training and an Internet connection. In this sense, the DER can serve a classroom with the size of the planet.

However, the assertion of repositories faces some problems that hinder their implementation and whose resolution does not depend directly on the bodies that control them, as already noted: the unavailability of broadband and the lack of resources to invest in hardware and software, for example. However, some of the limitations that affect access, use and collaboration, can be minimized by those responsible for the repositories. These aspects relate to the dimensions evaluated in this study: the visibility, policies, legal is sues, metadata and statistics.

The results of the evaluation of the two major Portuguese repositories of DER for the elementary and secondary education are condensed in Figures 8 and 9. In them it is shown the result of a SWOT analysis summarizing the main conclusions of this study. The use of this type of analys is in a study of this nature brings clear added value, once it facilitates the synthesis and the reading of results, it allows us to highlight the strengths and weaknesses of the repositories, relating them to, respectively, the opportunities and threats, also present.

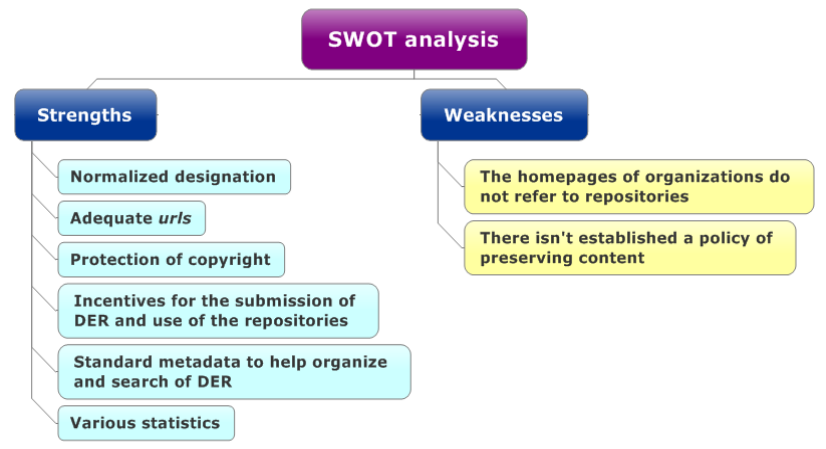

Figure 8. Strengths and Weaknesses of the two major repositories

- The two repositories have good visibility on the web, which opens an excellent opportunity for a fast increase in the number of producers and users. As it is shown in previous studies, repositories have great potential in promoting change in teaching and learn ing practices. For their visibility, the analysed repositories may indeed play a catalytic role in that change;

- The fact that the repositories have a well-defined policy for protecting copyright, it favours the spread of ethically correct behaviour in the production and use of DER;

- The incentives for the production and use of DER open a vast field of opportunity in reducing the info-exclusion, promoting and supporting a culture of lifelong learning, even in in formal contexts;

- The standardized metadata facilitate the research of DER within the repositories, minimizing one of the biggest problems when you are faced with a huge volume of material: the difficulty to find them;

- The existence of various statistics on the access to the repository, viewing and downloads of DER is valuable to the responsible entity, in that it provides information on the dynamics of the repository which is central for its management. It is also important for authors and users that can, 
respectively, follow the spread of their resources or have, for example, an indication of the DER's popularity in a given subject area.

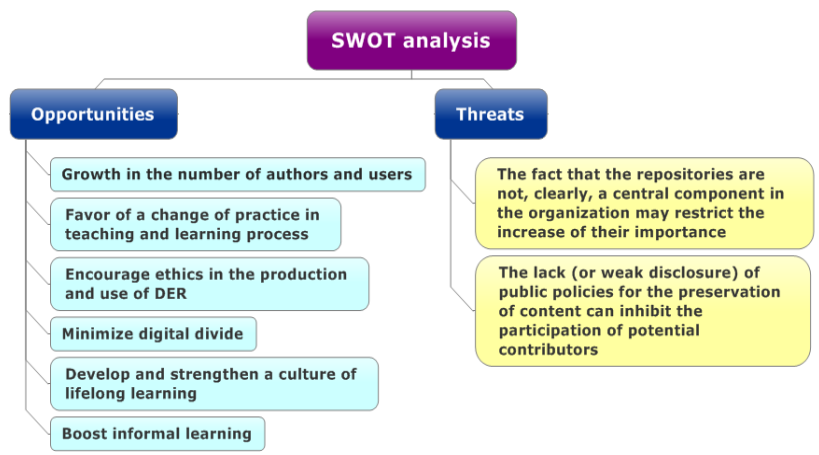

Figure 9. Opportunities and Threat s of the two major reposit ories

- The homepages of the entities holding the repositories do not refer to them, wh ich may indicate a less central role in institutional policies, or at least that this role is not adequately emphasized. This poses two threats: the repository has its implementation more constrained and it may be less valuable, too, by the target audience;

- The non-definition of a public policy of preserving data may be associated with the threat of the lack of confidence of the authors in the safety of their content, inhibiting, possibly, their collaboration.

We think that the repositories which have been the subject of our study may evolve towards the improvement of their quality, taking into account the limitations, weaknesses or threats identified and shaped here.

However, we believe that the potential diagnosed show that the two repositories constitute an excellent opportunity for the integration of Information and Communication Technology in teaching and learning environments in Portugal.

Thus, the evaluated repositories are not only facilitators of authors' collaboration and users/teachers' access in general, but they also help to pro mote the exercise of new practices in the classroom by Portuguese teachers in elementary and secondary schools in Portugal.

\section{The Future}

Although the DER is free for the user, it does not mean that there is no financing costs or costs with services needed to create and distribute a resource[31]. The production of open educational resources can therefore involve a large-scale investment. The DER should however be sustained, that is to say, have long-term viability. The concept of sustainability in addition to the cost of the resource, must also take into account the resource itself, i.e., if the resource consists, for example, of content in a specific piece of software, then it is important to consider the sustainability of the software[31]. The nature of DER has an impact on how they can be used and reused - an image can be pasted into a document but a book cannot. Therefore, sustainability re- quires the creation of content that can be tailored to the needs of users, being thus sustainability synonymous of reusability. This is also an issue that is related to the content and not only to technical issues[31] and therefore to be considered by the keepers of the repositories.

In order to have a sustained practice of DER adoption, there are factors that must be taken into account:

\subsection{Of Pedagogical Order}

- The relevance of the content and the adequacy to purposes of teachers;

- The provenance with a seal of quality: teachers appreciate resources that have been developed explicitly for educational purposes or can be easily used for that purpose;

- Granularity: teachers look for images, short audio or video clips or texts to integrate into their lesson plans. And often when they have to teach topics with which they are less comfortable, using DER can help;

- Although the media included in DER is considered as a means to help students visualize and understand more complex concepts, they must be accompanied by a script of operation[20].

\subsection{In Terms of Attitude}

- In order for teachers to use DER it is necessary to have a positive attitude to the reuse and sharing of resources, along with a perspective of collaboration;

- Recognition that the combination of material of their own authorship with other relevant ones from other sources is valuable, in what concerns the improvement of the teaching and learning process (strategy followed by the House of Sciences);

- Confidence to share their own materials;

- A sense of responsibility to encourage similar attitudes among colleagues[20].

Teachers, though willing to use resources authored by others, need to have freedom and flexibility to make the ownership of these resources in the teaching and learning process with their students.

Thus, the impact on teachers' individual practices is more likely to be achieved within the dimension of a social practice: networks of individuals who think the same way and who are receptive to ideas and suggestions from each other and willing to share their own resources. These networks should be promoted by schools with this human capital[20].

A student-centred approach to DER requires a shift from teacher-centred education to an environment that meets the needs of the student[32]. However Maddux[in 15] states that such a sift requires a complete change of values related to school culture, teaching and learning.

The use of DER in the classroom is also strongly related to teachers' epistemological orientations, with their theories and perceptions about the process of teaching and learning[15].

Therefore, a true integration of the DER in the process of teaching and learning requires that teachers consider the 
technology, content and pedagogy in a holistic manner, in the complex relationships in the educational system defined by three key components: i) knowledge of the pedagogy that is applicable to specific content; ii) knowledge of how technology can support educational goals and iii) knowledge of how the curriculum content is transformed by the application of technology[33].

Clearly, the teachers' technological knowledge alone is not suffic ient to achieve results using DER in the process of teaching and learning. It is also important to consider how the DER can support the educational goals set by the teacher and how content is transformed through technology[32].

Repositories focused on people, in the community of educational actors and in pedagogical practices with a view to professional development, will help overcome the individual and organizational inertia and barriers, towards a growing success near its users.

The success and effectiveness of the repositories of DER, as fundamental tools in pedagogical re-engineering, which echoes in teaching practices with wider horizons, more interactive and shared, depend on these assumptions when the policies are established. The two Portuguese repositories that we have studied began this journey in 2009 and have already incorporated many of these principles, which explain why they have managed to increase their momentum over these three years. However, there is still some path to go so that, in a more general way, they contribute to a sustained change of practice of users.

\section{ACKNOWLEDGEMENTS}

The authors wish to acknowledge the coordination and the team of Casa das Ciências, Portal das Escolas and GEPE for some of the data provided.

\section{REFERENCES}

[1] Atkins Daniel E., Brown, John S., Hammond Allen L., "A Review of the Open Educational Resources (OER) Movement: Achievements, Challenges and New Opportunities”, The William and Flora Hewlett Foundation. Online Available: http://www.oerderves.org/wp-content/uploads/2007/03/a-rev iew-of-the-open-educational-resources-oer-movement-final. pdf, 2007.

[2] Maron L. Nancy, Smith K. Kirby, Loy Mathew "Sustaining Digital Resources: An On-the-Ground View of Projects Today. Ithaka Case Studies in Sustainability", JISC, Online Available: www.jisc.ac.uk/contentalliance, 2011.

[3] Gurell Seth, Wiley, David, "Open Educational Resources Handbook 1.0 for Educator", (D. Wiley, Ed.). Center for Open and Sustainable Learning. Online Available: http://www.wikieducator.org/OER_Handbook/educator, 2008.

[4] Carson Steve, "The unwalled garden: growth of the Open-
CourseWare Consortium, 2001-2008", Open Learning, vol. 24, no 1, pp. 23-29, 2009.

[5] Nam C. S., Smith-Jackson, T. L., "Web-Base Learning Environment: A Theory-Based Design Process for Development and Evaluation", Journal of Information Technology Education, vol 6, pp. 23-43. Online Available: http://www.jite.or g/documents/Vol6/JITEv6p023-043Nam145.pdf, 2007

[6] Johnson L, Levine A, Smith R, Stone S, "The 2010 Horizon Report", Austin, Texas, The New Media Consortium, USA, 2010.

[7] OECD, "Giving Knowledge for Free. The Emergence of Open Educational Resources", Paris, France, 2007.

[8] Ramos José Luís, Teodoro Vitor Duarte Fernandes João Pedro S., Ferreira Manuel, Fernandes, Chagas Isabel, "Portal das Escolas: Recursos Educativos Digitais para Portugal. Estudo Estratégico", Lisboa: GEPE. Online Available: http://www.gepe.min-edu.pt/np4/364.html, 2010.

[9] Poulsen L. H., EdReNe colleagues, State of the art-I. Educational Repositories in Europe, 2008

[10] Margaryan, Anousch, Milligan, Collin, Douglas, Peter, "Structured Guidelines for setting up Learning Object Repositories". Online Available: CDLOR, http://www.acade my.gcal.ac.uk/cd-lor/documents/CD-LOR_Structured_Guide lines_v1p0_001.pdf, 2007.

[11] Johnson Larry, Adams S., Haywood K., "The NMC Horizon Report 2011 K-12 Edition”, Austin, Texas: The New Media Consortium, 2011.

[12] Davis Hugh C, Carr Leslie, Hey M N Jessie, Howard Yvonne, Millard David, Morris Debra, White Su "Bootstrapping a Culture of Sharing to facilitate Open educational Resources", IEEE Transactions on Learning Technologies, vol. 3, pp. 96-109, 2010.

[13] Combes B., Vali, R., "The future of learning objects in educational settings", In K. Harman, A. Koohang (Eds.), Learning objects: Applications, implications and future directions, Santa Rosa, CA: Informing Science Press, pp. 423-461, 2007.

[14] Govindasamy, T., "Successful implementation of e-learning: Pedago gical considerations", The Internet and Higher Education, vol. 4, pp. 287-299, 2002.

[15] Hadjerrouit Said, “A Conceptual Framework for Using and Evaluating Web-Based Learning Resources in School Education", Journal of Information Technology Education, no. 9, pp. 53-79, 2010.

[16] Dyer J H, Nobeoka, K, "Creating and managing a high performance knowledge-sharing network: The Toyota case", Strategic Management Journal, vol. 21, pp. 345-267, 2000.

[17] Lin H F, "Effects of extrinsic and intrinsic motivation on employee knowledge sharing intentions", Journal of Information Science, vol. 33, pp.135-149, 2007.

[18] Utdanningen, S. I., "Quality criteria for digital learning resources Version 1.0.", Senter for IKT I Utdanningen. Online Available: kvalitek.iktsenteret.no/files-itu/kvaliteskriterier_ EN.pdf, n. d.

[19] Højsholt-Poulsen Leo, EdReNe, "State of the art_I. Educational Repositories in Europe", ed: EcontentPlus, 2008.

[20] Masterman L., Wild J., "JISC Open Educational Resources 
Programme: Phase 2. OER Impact Study”. JISC. Online Available: http://www.jisc.ac.uk/media/documents/program mes/elearnin g/oer/JISCOERImpactStudy ResearchReportv10.pdf, University of Oxford, 2011.

[21] GEPE, "Portal das Escolas. Estudo de Implementação”, ME, GEPE, Lisboa, 2009.

[22] Pawlowski J, Zimmermann, V, “Open Content: A Concept for the Future of ELearning and Knowled ge Management", in Conference proceed ings Knowtech, 2007.

[23] Margary an Anousch, Currier Sarah, Littlejohn Allison, Nicol, David, "CD LOR Deliverable 1: Report on Learning Communities and Repositories". Glasgow: JISC. Online Available: http://www.ic-learning.dundee. ac.uk/projects/CD-LOR/deliv erable1_learningcommunitiesreport.doc, 2006.

[24] GEPE, "Educação em números - Portugal 2011", Lisboa: Ministério da Educação. Online Available: http://www.gepe min-edu.pt/np4/?newsId=643\&fileName=Educacao emnume ros2011.pdf, 2011.

[25] Ministério da Educação e Ciência, "Portal das Escolas", Online Available: https://www.portaldasescolas.pt/portal/ser ver.pt/community $/ \mathrm{p} \% \mathrm{C} 3 \% \mathrm{~A} 1$ ginas $/ 243 /$ perguntas_frequente s/15212, 2012.

[26] Ministério da Edu cação, Portaria n. ${ }^{0} 731 / 2009$ de 7 de Julho, "Sistema de formação e certificação de competências TIC para docentes", Diário da República, 1. a série - N. ${ }^{\circ} 129-7$ de julho de 2009. Online Available: http://www.pte.gov.pt/pte/P
T/Projectos/Projecto/index.htm?proj=47, 2009.

[27] Fundação Calouste Gulbenkian, "Casa das Ciências", Online Available: http://www.casadasciencias.org/index.php?option $=$ com_content $\&$ view $=$ article $\&$ id $=16 \&$ Itemid $=46 \&$ menu $=2 \&$ intro $=1,2012$.

[28] Vilelas, José, "Investigação - O Processo de constução do conhecimento", Edições Sílabo, Lisboa, 2009.

[29] López Alicia (Coord.), “Guía paar Evaluación de Repositorios Institucionales de Investiga ción”, Ministerio da Ciencia e Innovación de España, FECYT, Recolecta e CRUE, 2010.

[30] StatCounter, "StatCounterGlobal Stats - Top 5 Browsers in Portugal". Online Available: http://gs.statcounter.com/\#brow ser-PT-monthly-201203-201204, 2012.

[31] Downes S., "Models for Sustainable Open Educational Resources". Interdisciplinary Journal of Knowledge and Learning Objects, vol. 3, pp. 29-44. Online Available: http:// www.ijklo.org/volume3/IJKLOV3p029-044-Downes.pdf, 2007.

[32] John P., Sutherland R., "Teaching and learning with ICT: New technology, new pedagogy?", Education, Communication \& Information, vol. 4, no. 1, pp. 101-107, 2009.

[33] Jimoyiannis A., Komis, V., "Examining teacher's beliefs about ICT in education: Implications of a teacher preparation programme". Teacher Development, vol. 11, no. 2, pp. 149-173, 2007. 